Z. Klin. Chem. Klin. Biochem.

13. Jg. 1975, S. 351-353

\title{
Fetal and Maternal Plasma Cortisol Levels During Labour and after Delivery in the Human
}

\author{
By P. Knapstein, Marie Gündel, E. Lanz, D. Lommer and K. Sinterhauf
}

Universitäts-Frauen- and I. Medizinische Klinik, Mainz

(Eingegangen am 14. März 1975)

Summary: In a group of 15 cases the cortisol concentrations were determined in fetal and maternal plasma during labour and after delivery. In maternal plasma the levels were about twice as high as in fetal plasma and rose up to more than $1000 \mu \mathrm{g} / 1$ during labour $(\overline{\mathrm{x}}=639 \pm 222)$. After delivery the concentrations decreased. In fetal plasma, cortisol increased during labour from $\bar{x}=173 \pm 48$ to $\bar{x}=276 \pm 75$ at the time of delivery and decreased to $\bar{x}=106 \pm 36$ within the first 23 hours. In a second group of 20 cases maternal and umbilical cord blood and blood of the newborn during the first 28 hours after delivery were analyzed. The values were in the same ranges as in the first group. Extremely high maternal levels were not correlated to higher fetal values. The cortisol levels of postmature children did not significantly differ from those of normal babies.

\section{Foetale und mütterliche Cortisolspiegel im Plasma von Menschen während Wehen und nach Entbindung}

Zusammenfassung: In 15 Fällen bestimmten wir die Cortisolkonzentration im fetalen und mütterlichen Plasma während und nach der Geburt. Die Werte der Mutter lagen jeweils etwa doppelt so hoch wie die des Kindes und zeigten während der Wehentätigkeit einen Anstieg, wobei Spiegel von über $1000 \mu \mathrm{g} / 1$ erreicht wurden ( $\overline{\mathrm{x}}=639 \pm 222)$. Nach der Entbindung fielen die Werte wieder ab. Auch im fetalen Plasma stieg das Cortisol während der Geburt von $\bar{x}=173 \pm 48$ auf $\bar{x}=276 \pm 75 \mu \mathrm{g} / \mathrm{l}$ bei der Entbindung, um dann innerhalb der ersten 23 Stunden wieder auf $\bar{x}=106 \pm 36 \mu \mathrm{g} / \mathrm{l}$ abzufallen. In 20 weiteren Fällen wurde nur das mütterliche und das Nabelschnurblut sowie Blut während der ersten 28 Stunden nach der Entbindung analysiert. Die Werte zeigten ein gleichsinniges Verhalten wie in der ersten Gruppe.

Extrem hohe mütterliche Werte waren nicht mit auffallend hohen kindlichen Werten korreliert. Übertragene Kinder zeigten keine auffälligen Abweichungen des Cortisol-Spiegels.

\section{Introduction}

It has been suggested that rising fetal plasma cortisol levels are involved in the onset of labour in the sheep, goat, cow and rabbit $(1,2)$. Murphy (3) and Cawson (4), from their data on cortisol concentrations in umbilical cord blood after spontaneous or induced delivery, concluded that fetal cortisol is also important for spontaneous labour in the human. In the present study the changes in fetal and maternal plasma cortisol concentrations during labour and after delivery were investigated.

\section{Material and Methods}

All deliveries were monitored by continuous cardiotocography, blood gas values $\left(\mathrm{pH}, \mathrm{pO}_{2}, \mathrm{pCO}_{2}\right)$ in all samples taken and evaluation of the Apgar score of the newborn.

In a first group fo 15 unselected cases $0.1 \mathrm{ml}$ blood were withdrawn from the fetal scalp at $5 \mathrm{~cm}$ cervical dilatation, from the umbilical artery and vein and from a peripheral vein of the newborn 1 to 3 hours and 16 to 23 hours after delivery. At the same time intervals blood samples were taken from an antecubital vein of the mother.

In a second group of 20 cases umbilical cord and maternal blood at delivery and blood from the newborn and mother in the postpartum period were analyzed. The blood samples were heparinized and centrifuged in a Beckman 152 Microfuge. For triplicate cortisol determinations in $3 \times 0.01 \mathrm{ml}$ plasma rabbit antiserum against cortisol-21-hemisuccinate-bovine-albumin was used in the final dilution $1: 20000$. The method was described in detail by Veczsey et al. (5). The intraassay coefficient of variation, calculated from triplicate estimations in 183 samples was $3 \%$. For evaluation of statistical significance the T-test was applied and the linear contrast according to Scheffe was used. The cross reactivity of the antibody against progesterone was $5 \%$, against corticosterone $1,4 \%$, against compound $S 10 \%$.

\section{Results}

In the first group of 15 cases fetal and maternal blood samples could be withdrawn 6 to 2 hours prior to delivery, at the time of delivery and in the postpartum 
period. The mean cortisol concentrations in maternal plasma rose from $585 \pm 208$ in the prepartum period to $639 \pm 222$ at the time of delivery and decreased to $413 \pm 169 \mu \mathrm{g} / \mathrm{l}$ in the postpartum period. The difference of the mean values was not significant $(p=0.5)$ owing to the high variation of individual values. But considering the changes in individual patients the differences were significant. In 9 cases plasma cortisol levels increased by 20 to $120 \%$ during labour, in 3 cases there was no change, in 3 cases under continuous epidural anesthesia even a decrease could be observed. In the postpartum period the decreases were more or less pronounced.

Figure 1 demonstrates maternal and fetal mean values with 6 examples of individual curves. Case No. 19 was under epidural anesthesia.

The mean values of fetal plasma in all stages of delivery and the individual values in all cases were significantly lower than the corresponding maternal cortisol levels. The mean value from the fetal scalp in the prepartum period was $173 \pm 48$, from umbilical artery $276 \pm 75$, and from the postpartum period $106 \pm 36 \mu \mathrm{g} / \mathrm{l}$.

The statistical differences of all three mean values were highly significant $(p<0.001)$. Considering the individual changes an increase of more than $70 \%$ during labour could be stated in 13 cases. Only in 3 cases (for example No. 19 in fig. 1) with epidural anesthesia did fetal cortisol levels remained in the same range. In all newborns the plasma cortisol decreased by more than $90 \%$ in the first 23 hours after delivery.

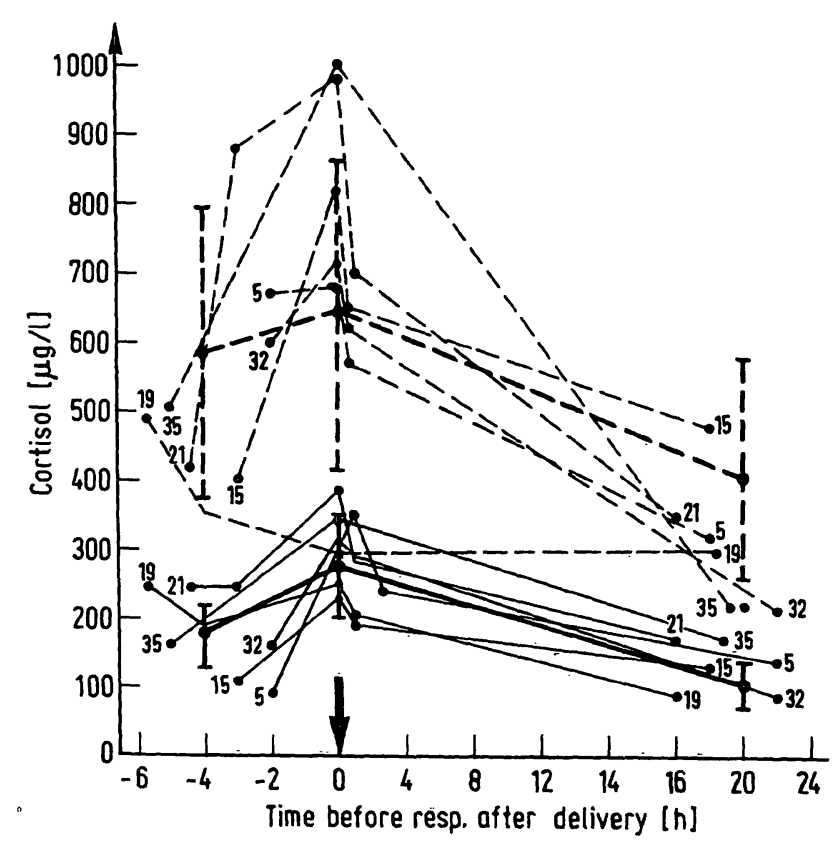

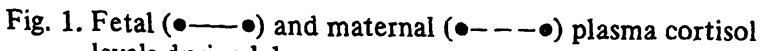
levels during labour.

Six individual curves and $x \pm s(n=15)$. Case Nr. 19 was under epidural anesthesia.
In 5 cases the cortisol concentrations in blood from the fetal scalp, taken inmediately after delivery, was compared to the values from umbilical artery. The mean values were $285 \pm 29$ and $276 \pm 55 \mu \mathrm{g} / 1$ resp., without significant difference.

In the second group of 20 cases blood samples from mother and newborn were taken at delivery and from the child 1 to 3 and 16 to 28 hours thereafter. The mean cortisol level of maternal plasma samples was $634 \pm$ $215 \mu \mathrm{g} / 1$. The mean value of umbilical arteries was $285 \pm 118$, of umbilical veins $306 \pm 133 \mu \mathrm{g} / \mathrm{l}$ (no statistical difference arteries-veins, $p=0.6$ ). The mean cortisol concentration of the newborn dropped to $96 \pm 42 \mu \mathrm{g} / \mathrm{l}$ in the postpartum period. The difference versus the mean values of umbilical cord plasma was highly significant $(p<0.001)$.

In the total material of 35 cases 7 children were born more than 9 days prior to term, 10 children were born with signs of postmaturity more than 9 days after term as calculated from the day of the last menstrual period. In the first group $(n=7)$ the mean cortisol level of maternal plasma was $710 \pm 212$, of umbilical artery plasma $243 \pm 37 \mu \mathrm{g} / \mathrm{l}$. In the second group $(\mathrm{n}=10)$ the corresponding mean values were $689 \pm 231$ or $270 \pm 82 \mu \mathrm{g} / 1$ resp. There was no statistical difference in maternal or newborn cortisol levels in the two groups.

The question was raised of whether there existed a correlation between high maternal and significantly elevated fetal concentrations. The cortisol levels in maternal plasma at delivery could be extremely high, in 20 cases between 610 and $1030 \mu \mathrm{g} / 1$ (mean = $776 \pm 143$ ), in 13 cases between 280 and $580 \mu \mathrm{g} / 1$ (mean $=432 \pm 93$ ). The mean values from umbilical arteries in these two groups were $293 \pm 107(n \neq 20)$ or $212 \pm 75 \mu \mathrm{g} / 1(\mathrm{n}=13)$ resp. The mean values from maternal plasma were different $(p<0.001)$, but no statistical difference of the mean umbilical artery values could be established $(p=0.6)$.

\section{Discussion}

The data show a remarkable increase of maternal as well as of fetal plasma cortisol levels during labour, in some cases of more than $100 \%$. No increase could be stated under continuous epidural anesthesia ("painless delivery", without central nervous inhibition). Therèfore the changes can be interpreted as general reaction during a stress situation. Extremely high maternal levels were not significantly correlated to higher fetal values. But no definite conclusions can be drawn concerning the origin of rising fetal plasma cortisol.

In our material the postmature newborns did not have significantly lower cortisol levels than babies born prior to or at term. From the present results of dramatically changing concentrations during the process of labour it 
seems of doubtful validity to draw any conclusions on the role of fetal cortisol in the onset or maintenance of labour from the cortisol levels in umbilical cord plasma alone.

\section{References}

1. Strott, Ch., Sundel, H. \& Stahlmann, M. (1974), Endocrinology 95, 1327-1332.

2. Liggins, G., Kennedy, P. \& Holm, L. (1967), Amer. J. Obstet. Gynecol. 98, 1080-1091

3. Murphy, B. (1973), Amer. J. Obstet. Gynecol. 115, 521-528.

\section{Acknowledgement}

We thank Dr. P. Veczsey (Pharmakologisches Institut, Universität Heidelberg, Germany) for generous gift of the antiserum against cortisol-21-hemisuccinate-bovine-albumin.
4. Cawson, M., Anderson, A., Turnball, A. \& Lampe, L. (1974), J. Obstet. Gynec. Brit. Cwlth. 81, 737-739.

5. Veczsey, P., Penke, B., Cassy, K. \& Bacck, L. (1972), Experientia $8,1104-1105$.
Prof. Dr. P. Knapstein

Universitäts-Frauenklinik

Langenbeckstr. 1

D-6500 Mainz 
